\title{
Autism Spectrum Disorder
}

National Cancer Institute

\section{Source}

National Cancer Institute. Autism Spectrum Disorder. NCI Thesaurus. Code C88412.

A spectrum of developmental disorders that includes autism, Asperger syndrome, and Rett syndrome. Signs and symptoms include poor communication skills, defective social interactions, and repetitive behaviors. 